\title{
Educação ambiental no Parque Estadual das Fontes do Ipiranga (São Paulo, SP, Brasil): um panorama sobre os programas educativos e sua relação com a Unidade de Conservação ${ }^{1}$
}

\author{
(D) $\underline{\text { Caio Henrique de Araújo-Bissa }}^{2,3}$ e Haydée Torres de Oliveira $^{2}$
}

Recebido: 14 março 2019; aceito: 9 outubro 2019

Como citar: Araújo-Bissa, C.H. \& Oliveira, H.T. 2019. Educação ambiental no Parque Estadual das Fontes do Ipiranga (São Paulo, SP, Brasil): um panorama sobre os programas educativos e sua relação com a Unidade de Conservação. Hoehnea 46: e222019. http://dx.doi.org/10.1590/2236-8906-22/2019.

ABSTRACT - (Environmental education in the Parque Estadual das Fontes do Ipiranga (São Paulo, SP, Brazil): an overview of educational programs and their relationship with the protected area). This research aimed to understand the elaboration and implementation of educational activities in the institutions open to visitation in the Parque Estadual das Fontes do Ipiranga (PEFI). Educational activities were analyzed from the perspective of the Management Plan in order to make suggestions for a unified program of environmental education for PEFI. Through a qualitative approach, interviews were conducted with those responsible for the educational programs of the PEFI institutions. The educational activities are independently developed by each institution and focused on the visitors. PEFI is not the main theme in practically any activity, except in a museum in the São Paulo Botanical Garden and in an educational space in the São Paulo Zoo. We realized the need to structure an educational program for the PEFI. We suggest that such structuring be carried out from a dialogical perspective, involving groups related to PEFI and considering the local reality.

Keywords: Conservation Unit, educational activities, management plan, participation

RESUMO - (Educação ambiental no Parque Estadual das Fontes do Ipiranga (São Paulo, SP, Brasil): um panorama sobre os programas educativos e sua relação com a Unidade de Conservação). Esta pesquisa buscou compreender como são elaboradas e realizadas as atividades educativas nas instituições do Parque Estadual das Fontes do Ipiranga (PEFI) que recebem visitantes, analisá-las sob a ótica do Plano de Manejo e trazer sugestões para um programa de educação ambiental unificado para o PEFI. Em uma abordagem qualitativa, foram realizadas entrevistas com as responsáveis pelos programas educativos das instituições do PEFI. As atividades educativas analisadas são desenvolvidas independentemente por cada instituição e focam em suas/seus visitantes. O PEFI não é a principal temática em praticamente nenhuma atividade, sendo mais abordado em um museu no Jardim Botânico de São Paulo e em um espaço educador no Zoológico de São Paulo. Percebemos a necessidade de se construir um programa educativo para o PEFI. Sugerimos que esta construção seja realizada sob uma perspectiva dialógica, envolvendo os grupos relacionados ao PEFI e considerando sua realidade, bem como a população de seu entorno. Palavras-chave: atividades educativas, participação, plano de manejo, Unidade de Conservação

\section{Introdução}

Desde os anos 1960, o cuidado com o meio ambiente vem, cada vez mais, se demonstrando como uma necessidade para um futuro sustentável e saudável em nosso planeta. É fato que, para isso ser possível, é importante que exista uma reflexão sobre como nos relacionamos com o meio ambiente. Neste contexto, surge a Educação Ambiental (EA) com o papel de possibilitar essa reflexão e buscar um melhor relacionamento com o meio ambiente, por meio da construção de valores, habilidades, atitudes, tanto individuais quanto coletivas, garantindo a conservação da natureza e a qualidade de vida (Brasil 1999).

1. Parte da Dissertação de Mestrado do Primeiro Autor

2. Universidade Federal de São Carlos, Departamento de Ciências Ambientais, Rodovia Washington Luís, km 235, 13565-905 São Carlos, SP, Brasil

3. Autor para correspondência: caiohabissa@gmail.com 
A constatação da consolidação da EA para a conservação da natureza pode ser feita ao analisarmos importantes eventos mundiais. Alguns eventos que podemos citar, cronologicamente, são: a I Conferência Mundial do Meio Ambiente Humano, promovida pela ONU, em Estocolmo, na Suécia, em 1972, quando a EA é indicada como estratégia para solução da crise ambiental; o Seminário Internacional sobre Educação Ambiental (1975), na Iugoslávia, realizado pela Organização das Nações Unidas para a Educação, a Ciência e a Cultura (UNESCO), no qual é definida a estrutura básica da EA; a Conferência Intergovernamental de Educação Ambiental, em Tbilisi, na Geórgia (1977) quando foram definidas estratégias, objetivos e critérios para a EA nacional e internacional. E, finalmente, a Conferência das Nações Unidas do Meio Ambiente e Desenvolvimento, a Rio92 ou ECO-92, durante a qual é aprovado Tratado de Educação Ambiental para Sociedades Sustentáveis e Responsabilidade Global (Oliveira \& Logarezzi 2013).

Em decorrência a essa movimentação global, o Brasil teve como uma de suas respostas a inclusão da EA em sua legislação. Alguns exemplos são a Política Nacional do Meio Ambiente (Brasil 1981) e a Constituição Federal (Brasil 1988), as quais são as primeiras leis a tratarem da EA. Neste momento, a EA é tida como um caminho para garantir a preservação do meio ambiente e a promoção do direito de todos a um meio ambiente adequado, devendo ser aplicada a todos os níveis de ensino. No intuito de regulamentar o que está garantido na Constituição Federal foi elaborada e promulgada a Política Nacional de Educação Ambiental (Lei ${ }^{\circ}$ 9.795/99), sendo um dos principais documentos que direcionam a EA no Brasil; o Decreto $\mathrm{n}^{\mathrm{o}}$ 4.281/02 que regulamenta a Política Nacional de Educação Ambiental (Brasil 2002); e o atual Programa Nacional de Educação Ambiental (ProNEA) (Brasil 2005).

Ainda dentre a legislação brasileira, é importante citarmos o Sistema Nacional de Unidades de Conservação (SNUC) (Brasil 2000) e o Plano Estratégico Nacional de Áreas Protegidas (PNAP) (Brasil 2006), importantes documentos para a conservação da natureza de nosso país. O SNUC ressalta a importância da EA quando indica que um de seus objetivos é fornecer condições e promovê-la. Já o PNAP utiliza a EA como estratégia para alcançar seu objetivo de fortalecer a educação, comunicação e participação pública para que haja participação e controle social sobre o SNUC e, também, para impedir e mitigar impactos negativos às Unidades de Conservação (UC).

Dessa maneira, a EA pode ser considerada uma estratégia a ser aplicada nas UCs para garantir a conservação da natureza. Para Padua (2012), um dos objetivos da EA em UCs é compartilhar a temática ambiental com a população do entorno e com a sociedade em geral, o que possibilitará a participação efetiva para a conservação da natureza. Assim, a EA nas UCs tem como papel a construção de diálogo para o desvelamento e resolução de conflitos, permeado por um processo educativo que pode construir novas relações entre natureza e sociedade (Mendonça 2005). Atualmente os programas de EA em UCs são compostos por atividades como: visitas monitoradas à UC com o público escolar, palestras ou reuniões para discussões de assuntos referentes aos diferentes grupos envolvidos com a área protegida, exposições, cursos de formação de funcionárias/os da UC ou de professoras/es e alunas/os de graduação, elaboração de material educativo, cursos de férias (Rocha 1997), além de trilhas interpretativas (Menghini et al. 2007) e as vivências com a natureza (Mendonça 2007). Outra linha da EA é a gestão participativa das UCs, principalmente porque, a partir da EA é possível mobilizar a população ligada à UC de modo a viabilizar sua participação efetiva na gestão destas áreas (MMA 2011).

Uma UC de grande importância, principalmente quando consideramos seu contexto social e geográfico, é o Parque Estadual das Fontes do Ipiranga (PEFI). Criado em 1969, o PEFI é uma UC de proteção integral localizada no município de São Paulo, SP, fazendo limite também com Diadema, SP (Fernandes et al. 2002). A vegetação predominante é classificada como ombrófila densa, pertencente ao domínio da Mata Atlântica (Barbosa et al. 2002).

O PEFI é completamente envolvido pela malha urbana, de um lado há a Rodovia dos Imigrantes, de outro a Avenida do Cursino e, atravessando o parque, a Avenida Miguel Estéfano, formando assim uma verdadeira ilha verde em meio ao espaço urbano. Além disso, o PEFI possui algumas características que o diferenciam de outras UCs de mesma categoria, como o fato de, em seu interior, estarem presentes instituições governamentais como o Instituto de Botânica e o Jardim Botânico de São Paulo, o Instituto de Astronomia, Geofísica e Ciências Atmosféricas e o Parque Cientec, a Fundação Parque Zoológico de São Paulo composta pelo Jardim Zoológico e Zoo Safári, o $3^{\circ}$ Batalhão da Polícia, a $97^{a}$ Delegacia da Polícia 
Civil ( $\left.97^{\circ} \mathrm{DP}\right)$, o Centro de Atenção Integrada em Saúde Mental (CAISM) "Doutor David Capistrano da Costa Filho", e o Centro Paralímpico Brasileiro.

Atualmente, três destas instituições recebem visitantes e possuem um programa educativo com enfoque na educação ambiental. São elas: o Jardim Botânico de São Paulo (JBSP), a Fundação Parque Zoológico de São Paulo (FPZSP) e o Parque Cientec. Anualmente, somente a FPZSP recebe cerca de 1,5 milhão de pessoas (FPZSP 2014), o que demonstra o enorme potencial e oportunidade que o PEFI tem para a realização de projetos e ações educativas, possibilitando grande difusão da temática ambiental. Além disso, o PEFI conta com um plano de manejo desde 2008, no qual, reconhecendo este potencial, a EA é colocada como um dos nove programas para que a UC possa alcançar seus objetivos. As atividades propostas no programa Educação são: "Implementar proposta de conscientização dos funcionários dos órgãos instalados no PEFI e dos moradores do entorno; e articular as diversas instituições do PEFI para implementar proposta de educação ambiental para visitantes." (SMA 2008).

Considerando estes fatos, esta pesquisa teve como objetivo principal compreender como são elaboradas e realizadas as atividades educativas nas instituições do PEFI que recebem visitantes, analisá-las sob a ótica do Plano de Manejo e trazer sugestões para um programa de educação ambiental unificado para o PEFI.

\section{Material e métodos}

A pesquisa utilizou uma abordagem qualitativa com cunho exploratório. Partindo do pressuposto que a melhor compreensão de um fenômeno se dá no contexto no qual ele ocorre, a obtenção de dados acontece por contato direto com a situação estudada, de maneira a ser possível a compreensão da visão de quem participa da pesquisa (Godoy 1995a, b). Quanto à pesquisa exploratória, Triviños (1987) indica a vantagem ser o fato dela permitir que a pesquisadora ou pesquisador aumente sua experiência com relação a determinado problema.

A pesquisa foi realizada em três instituições que estão inseridas no PEFI e possuem um programa educativo: Jardim Botânico de São Paulo (JBSP), Fundação Parque Zoológico de São Paulo (FPZSP) e o Parque Cientec. A coleta de dados nesta pesquisa ocorreu em 2015. Foram realizadas entrevistas semiestruturadas com as educadoras responsáveis pelos programas educativos de cada instituição pesquisada.
As entrevistas semiestruturadas apresentam um roteiro com questões abertas que aceita adaptações quando necessárias (Lüdke \& André 1986). Esse tipo de entrevista permite a descrição, explicação e compreensão ampla de fenômenos dentro de situações em diferentes dimensões, bem como valoriza a presença de quem realiza a investigação e enriquece a pesquisa, pois permite, a partir de todas as perspectivas possíveis, que a pessoa entrevistada alcance tanto a liberdade quanto a espontaneidade necessária (Triviños 1987).

De maneira a garantir a ética nesta pesquisa, para todas as participantes, foi assinado o Termo de Consentimento Livre e Esclarecido, no qual constava a descrição e objetivos da pesquisa, o caráter não obrigatório e anônimo das entrevistas, bem como o contato e informações sobre os pesquisadores. Após a transcrição das entrevistas, enviamos o documento às entrevistadas para que pudessem fazer ou não alterações que achassem necessárias, garantindo que os dados trabalhados estivessem realmente de acordo com sua percepção, evitando possíveis mal-entendidos ou constrangimentos. Além disso, utilizamos nomes fictícios para a identificação das participantes de maneira a preservar, de alguma maneira, sua privacidade.

A análise dos dados foi realizada após a devolutiva das transcrições aplicando a Análise Textual Discursiva (ATD), descrita por Moraes \& Galiazzi (2007). Esta metodologia consiste em quatro fases: a unitarização, a categorização, a construção de um metatexto e a teorização. Na unitarização, o texto é analisado em detalhes, sendo fragmentado de maneira a destacar seus elementos constituintes, formando as unidades de análise. Quanto à categorização, são verificadas relações entre as unidades de análise, reunindo-as em conjuntos com elementos próximos, definindo assim as categorias. Estas podem ser estabelecidas a priori, a partir das teorias que fundamentam a pesquisa, o que é conhecido como método dedutivo; podem também ser estabelecidas a partir das análises das unidades de significado, obtendo-se categorias emergentes, pelo método dedutivo. Seguimos para o momento de construção de um metatexto, no qual constará a descrição das categorias utilizadas; finalizando com a teorização, na qual é realizada a interpretação dos dados obtidos para, em um esforço construtivo, ampliar a compreensão do fenômeno investigado.

Dessa forma, quando apresentadas citações das falas das entrevistadas, estas serão acompanhadas 
do nome fictício e da numeração correspondente às linhas da transcrição da entrevista, permitindo a sistematização dos dados.

\section{Resultados e Discussão}

Abordaremos a seguir os principais aspectos de cada um dos programas educativos das três instituições pesquisadas. De acordo com os objetivos desta pesquisa, será focada a relação entre as atividades educativas que abordam o PEFI e as que incluem a população do entorno, uma vez que a proposta do plano de manejo no programa "Educação" envolve as/os visitantes das instituições e a população do entorno. Foi realizado um levantamento das atividades educativas das instituições selecionadas, buscando compreender os seguintes aspectos: se haviam considerado o plano de manejo em sua construção, se a equipe recebia algum tipo de treinamento sobre o PEFI, se as atividades abordavam essa UC e, se eram voltadas à população do entorno. Salientamos que cada instituição dentro do PEFI tem um enfoque diferente, o que reflete diretamente em seus programas educativos. Dessa maneira, estes apresentam atividades com temas ligados à missão das instituições, que não necessariamente se ligam à temática desta pesquisa.

Outro ponto a ser considerado é a dificuldade em realizar comparações entre o PEFI e outras UCs de mesma categoria por conta da realidade do PEFI. Este parque não apresenta um programa de uso público, instrumento no qual muitas UCs costumam inserir a EA (Dias 2008, Wick 2014), uma vez que o acesso a sua área só é permitido nas instituições com finalidade de visitação. Além disso, as ações de educação são conduzidas por três instituições separadamente, cada qual com objetivos, equipes e metodologias diferenciadas. A seguir são apresentadas as análises das ações educativas de cada instituição.

Fundação Parque Zoológico de São Paulo (FPZSP) Composta pelo Jardim Zoológico e o Zoo Safari, esta instituição conta com um espaço de aproximadamente $4 \mathrm{~km}$ de alamedas e cerca 3200 animais de diferentes regiões do planeta (FPZSP 2019). O programa de EAé de responsabilidade da Divisão de Educação e Difusão (DED), que apresenta como equipe educadora: estagiárias/os, aprimorandas/os (participantes do Programa de Aprimoramento Profissional - PAP, que funciona similarmente a uma residência para recém-formadas/os), e as biólogas responsáveis pelo setor, totalizando uma equipe de aproximadamente 20 pessoas. Contudo, são as/os estagiárias/os que realizam a maior parte das atividades educativas na FPZSP, como nos conta a bióloga responsável pelo setor:

"Quem realiza, em geral, a maior parte das atividades, são os estagiários do programa de educação ambiental, porém algumas atividades mais especificas são realizadas pelos aprimorandos do programa de educação ou pelos biólogos da divisão." Alice 134.

Segundo a educadora da FPZSP, a equipe recebe frequentemente treinamentos sobre o funcionamento do Zoológico e sobre EA. Periodicamente, também são realizadas visitas técnicas a outras instituições com programas educativos, inclusive às instituições do PEFI. Contudo, a UC em questão é abordada apenas dentro de treinamentos cuja temática é a Mata Atlântica e, possivelmente, nas visitas técnicas às instituições do PEFI, não havendo um curso/ treinamento específico.

No momento desta pesquisa, a FPZSP realizava visitas monitoradas com diversas temáticas, variando do interesse de quem participa e faixa etária, são elas: Bastidores do Zoo, Passeio Noturno, Cadê o Lobo?, Mata Atlântica: conhecer para conservar, Plantando o Futuro, Resgatando nossa História, Visitas Monitoradas Técnicas (para cursos técnicos e faculdades), Visitas Monitoradas Especiais (para pessoas com deficiências). Além disso, o programa educativo da FPZSP incluía apresentações didáticas (em frente a recintos de alguns animais ou no Espaço "Vida de Bicho"), cursos de formação de professoras/ es (Curso "O Zoológico como instrumento de ensino" e "Programa Zooescola") ; clube para idosos (Clube Teteia) ; exposições temáticas e espaços educadores.

A educadora responsável nos informou que nenhuma dentre essas atividades, havia considerado o plano de manejo do PEFI. Nesta instituição, a elaboração de atividades se dá a partir de demandas das/os visitantes e da própria instituição. Com isso em mente, é realizado um diagnóstico das percepções do público visitante para elaboração da parte pedagógica, seguido da implementação e posterior avaliação da atividade.

Por outro lado, mesmo não tendo considerado o plano de manejo, algumas das atividades falam sobre o PEFI:

“[...] no [Espaço educador] 'Na trilha da Kinha'tem um enfoque ainda maior no PEFI, porque o espaço todo trata só de Mata Atlântica, [...] as capacitações que a gente realiza com professores também têm um 
enfoque grande na Mata Atlântica especialmente a do PEFI, tanto no curso 'Zoo como instrumento de ensino' quanto no 'Zooescola'. No clube Teteia sempre nos encontros de educação ambiental a gente também trabalha a questão do PEFI e eventualmente os outros setores quando vão abordar as temáticas das áreas deles eles também falam do PEFI, [...] apresentações didáticas a gente às vezes trabalha essa questão principalmente quando elas são temáticas, $o$ 'Vida de Bicho'também com cenários, dependendo do animal que vai ser apresentado, pode ser abordada a questão de unidades de conservação e falar do PEFI. Nas visitas monitoradas, a gente tem uma especifica sobre Mata Atlântica que fala sobre a fauna e outros aspectos do bioma e a gente enfoca na mata do PEFI. Essa visita também é a mesma que compõe o 'Zooescola'. No 'Passeio Noturno' [...] a gente também aborda a questão do PEFI principalmente na abertura do passeio quando a gente vai localizar as pessoas dentro do parque, a gente fala da importância do PEFI pra região, como controle climático, enfim, e a fauna de vida livre que existe aqui. [...] tem essa coluna no jornal 'Abrindo o Bico' que chama 'Espaço PEFI', em que a gente divulga coisas sobre o PEFI, então desde divulgar outras instituições, quanto divulgar características do PEFI, falar sobre a vegetação que é encontrada aqui, sobre os animais, sobre ele como um polo turístico, sobre ele como uma unidade de conservação, enfim, é uma coluna especifica pra matérias sobre o PEFI." Alice 42, 45, 47, 52, 56, 58, 61, 222.

A partir dessa fala, podemos sintetizar que, na FPZSP as atividades que abordam o PEFI são: um espaço educador, duas modalidades de visitas monitoradas, dois cursos de formação de professoras/ es, clube para idosos, apresentações didáticas e uma coluna em um jornal da instituição. A abordagem da temática é realizada principalmente destacando as funções socioambientais do PEFI, bem como sua biodiversidade, dessa forma, muitas vezes, situando a/o visitante e apresentando o PEFI.

A FPZSP conta também com materiais de apoio a essas atividades, destacamos dentre eles o livro utilizado no curso de formação de professoras/es "Programa Zooescola", intitulado "A Mata Atlântica como instrumento de ensino", o qual aborda um pouco da história, biodiversidade e serviços realizados pelo PEFI, tratando novamente a respeito de sua função socioambiental (Roberti \& Rancura 2010); e o livro que auxilia educadoras/es a planejar atividades e utilizar o Espaço educador "Na trilha da Kinha" no qual o PEFI é citado de maneira sucinta, buscando a apresentação da UC (Martins et al. 2015).

Com relação ao envolvimento da população do entorno nas atividades ou se alguma delas era voltada a esse público, a educadora da FPZSP nos conta que, naquele momento nenhuma atividade fazia isso:

"Diretamente, atualmente, não. [...]. Todas as nossas atividades são abertas para todas as pessoas que quiserem participar, então, por exemplo, as atividades que ocorrem no parque diariamente, desde que a pessoa acesse o parque, ela pode participar, [...] as atividades elas não são fechadas, porém têm pouca adesão do pessoal do entorno, não sei se até porque talvez o pessoal do entorno não frequente tanto $o$ Zoológico quanto se espera." Alice 260, 265, 270.

No entanto, no passado já existiram projetos voltados a essa população, inclusive com destaque ao PEFI. Um dos projetos realizados no âmbito do programa de aprimoramento profissional consistia em um curso de formação de professoras/es, apresentação para as/os estudantes sobre aspectos da Mata Atlântica utilizando-se de taxidermias, seguido da elaboração de projetos educativos por estas/es educadoras/es. O projeto chamava-se "Aula Animal" e esteve em funcionamento entre 2011 e 2012, mas devido a demandas e necessidades institucionais, o projeto não teve continuidade.

Parque Cientec - Esta instituição visa trabalhar principalmente na difusão da ciência e tecnologia (Mantovani \& Massambani 2004). Assim como na FPZSP, grande parte da equipe é formada por estagiárias/os, totalizando 37 pessoas. Segundo a educadora do Parque Cientec, a equipe realiza cursos para sua formação que trabalham a mediação e o conteúdo abordado nas atividades educativas. O PEFI é um dos assuntos abordados nesse conjunto de cursos:

"Agora, todo ano, assim a cada dois meses, um mês, eu convido alguém para vir falar sobre algum tema ou área. Então, todo ano tem palestra a respeito de vários temas, e sempre traz alguém falando, já veio do PEFI três vezes, [...] a gente faz esse tipo de intercâmbio de palestras para contribuir na formação deles. " Carla 355,358 .

O programa educativo do Parque Cientec trabalha principalmente com a realização de visitas monitoradas, embora a visitação espontânea seja permitida. Ele tem como foco a ciência e a tecnologia, se dividindo em três principais eixos: cosmos, 
ciências da natureza e meio ambiente. No primeiro, são abordados aspectos ligados à astronomia por meio de exposições interativas, como a Luneta Zeiss e o Planetário. No segundo, o foco é a física, geofísica e matemática, apresentadas por exposições de experimentos relacionados a esses campos do conhecimento. No terceiro eixo, com o foco no meio ambiente, são realizadas trilhas e experiências com microscópios. Além das visitas monitoradas, a instituição promove frequentemente palestras aos fins de semana sobre temas relacionados à ciência, tecnologia e meio ambiente.

Como visto anteriormente na FPZSP, nenhuma das atividades do Parque Cientec se utilizou do plano de manejo para sua elaboração. E, embora essas atividades não tenham o PEFI como o principal assunto, esta UC é abordada, com um caráter histórico e para situar o visitante, durante os dois modelos de trilhas realizados pela equipe desta instituição (Trilha educativa e Trilha dos ecossistemas), como indicado pela educadora responsável:

"[...] quando a escola chega aqui e no agendamento é colocado que o parque faz parte do Parque Estadual e ai tem algumas trilhas. Quando a escola chega, para as crianças: é uma área de preservação, a gente está no meio da Mata Atlântica. Então passa algumas informações a respeito mais da Mata Atlântica, da preservação do que especificamente do Parque das Fontes do Ipiranga. Comenta que tem as nascentes do Ipiranga. [...]. Situa.” Carla 206, 214.

A respeito do envolvimento da população do entorno nas atividades educativas do Parque Cientec, atualmente não há uma atividade diretamente voltada a esse público, embora, segundo nos indicou a educadora responsável, essas pessoas têm visitado mais frequentemente a instituição desde que a equipe começou a colocar faixas anunciando palestras e convidando para visitação.

No passado, o Parque Cientec também buscou trabalhar com a população do entorno com o projeto "Ciência Móvel", que levava experimentos científicos de fácil locomoção a escolas da região, mas o projeto precisou ser descontinuado por demanda de recursos e pessoal.

Jardim Botânico de São Paulo (JBSP) - Esta instituição possui uma área de 36 hectares de visitação, onde é possível observar plantas principalmente da Mata Atlântica, além de outros atrativos como: as Estufas Dr. Frederico Carlos Hoehne, com plantas do
Cerrado e Mata Atlântica; o Museu Botânico, que traz informações a respeito da história da botânica no Brasil, dos trabalhos realizados no Instituto de Botânica e sobre duas unidades de conservação de responsabilidade deste instituto; e a Trilha da Nascente, com 360 metros de extensão, construída de modo acessível, levando a/o visitante mata adentro até a nascente do córrego Pirarungáua, que forma o Riacho do Ipiranga (Jardim Botânico de São Paulo 2015).

Como o JBSP está ligado ao Instituto de Botânica, a EA é um dos núcleos de pesquisa deste instituto. Por isso, a equipe do JBSP é composta por uma pesquisadora, responsável pela EA no JBSP, um especialista ambiental, uma assistente técnica, uma secretária, e nove estagiárias/os. Como nas instituições anteriores, as/os estagiárias/os são aquelas/es que conduzem os trabalhos educativos com as/os visitantes e, para tal, também participam de cursos e palestras sobre o trabalho da mediação, sobre o PEFI, recebendo inclusive material didático em que a UC é abordada, além de terem a oportunidade de conhecer as pesquisas feitas por alunas/os de pós-graduação do Instituto de Botânica.

No momento da pesquisa, as atividades educativas no JBSP haviam passado por uma reformulação com relação às visitas monitoradas:

"Hoje, diante da demanda e diante do nosso número reduzido de monitores, nós não temos mais condição de fazer a visita monitorada, realizamos visitas educativas. Então nós nos organizamos hoje: os monitores ficam em locais mais atrativos do Jardim como estufas, trilha e museu. Quando a escola chega esse monitor ele dá algumas informações dependendo também do interesse da escola, então esse é um trabalho que nós fazemos aqui. " Bruna 50.

Além de monitores em pontos estratégicos do JBSP, como parte de seu programa educativo, a instituição conta também com uma série de placas interpretativas, exposições periódicas e a exposição do Museu Botânico.

Dentre essas atividades apresentadas, a educadora responsável nos informou que não foi considerado o plano de manejo do PEFI para sua construção e sim diretrizes específicas para jardins botânicos. Contudo, ao contrário do que foi visto na FPZSP e no Parque Cientec, o JBSP já seguiu o plano de manejo para elaborar uma atividade de gestão participativa com a população do entorno. 
Essa atividade envolveu moradores da Rua Alfenas, em Diadema, SP, que faz divisa diretamente com o PEFI, que pediam por melhorias na região. Ao mesmo tempo, eram observados problemas como lixo sendo descartado dentro do PEFI, bem como atos de violência dentro desta UC. Dessa forma, a equipe do JBSP articulou junto da equipe gestora do PEFI o contato com a prefeitura de Diadema. Assim, iniciou-se uma série de reuniões, denominadas de Conselho de Compromisso, com a população e os órgãos públicos de modo a definir como seriam essas modificações na área. Como resultado desse processo foram construídas pistas para caminhadas e áreas para exercícios físicos e, ao mesmo tempo, surgiram oportunidades para o desenvolvimento de processos educativos com essas pessoas. Sobre os principais resultados desse projeto, a educadora indica:

"Aquela comunidade teve vários ganhos ao longo do desenvolvimento desse projeto. Ganhos em termos de segurança, nós ensinamos várias coisas para aquela comunidade [...]. Eles ganharam calçadas para fazer caminhada, eles ganharam espaços de lazer que eles pediram, então as casas foram valorizadas no final do projeto. [...]. Esse projeto começou por conta de uma série de problemas que nós tínhamos, eu não vou te falar que solucionou todos os problemas porque isso é impossivel, mas o projeto solucionou $80 \%$ dos problemas." Bruna 352, 360, 368.

Este pode ser realmente considerado um projeto de sucesso, mas que já não estava mais em continuidade. Em se tratando do entorno do PEFI, o JBSP também teve outra experiência, o projeto "O Jardim Botânico vai à escola" que consistia em um curso para formação de professoras/es, oficinas com professoras/es e alunas/os, reuniões com as equipes educativas, e visita ao jardim botânico (Cerati 2011). A educadora também indicou que este projeto teve sucesso, inclusive para a divulgação do PEFI, mas pelo fato de não ter sido um projeto institucionalizado, este também não foi continuado.

Com relação à abordagem do PEFI nas atividades no JBSP, a UC é abordada principalmente no Museu Botânico, onde parte de uma sala trata a respeito de sua biodiversidade e função socioambiental, inclusive apresentando uma maquete da área. Além disso, as/ os monitoras/es podem abordar o PEFI em sua fala, principalmente na recepção de escolas, para situar quem visita o JBSP.

\section{Educação ambiental no PEFI}

Baseando-se nos dados apresentados anteriormente, podemos perceber algumas importantes características sobre o desenvolvimento da EA no PEFI.

Em primeiro lugar, nas três instituições há a presença de um departamento responsável pelas atividades educativas, com equipes formadas principalmente por estagiárias/os, que participam de cursos que permitem o aprimoramento contínuo dos conhecimentos e habilidades dessas pessoas, contribuindo para a formação dessas/es estudantes. Assim, podemos afirmar que tanto a FPZSP quanto o Parque Cientec e o JBSP reconhecem seu potencial para a educação não-formal, o valorizam e o colocam, na medida do possível, em prática com seus visitantes.

Toledo \& Pelicioni (2006) analisaram aspectos sobre os responsáveis pelos programas educativos em 18 Parques Estaduais paulistas, concluindo que tinham funções diferenciadas como monitores, técnicos e coordenadores de programa de uso público e, na grande maioria sem curso superior e formação específica em EA. No caso do PEFI, as três educadoras estão alocadas em setores específicos que têm entre outras atribuições o desenvolvimento de ações educativas, o que permite uma melhor eficiência e um olhar mais atento às atividades. Além disso, embora com formação não específica em EA, as três educadoras têm grande experiência profissional na área da educação e um grau de formação elevado.

Todas as equipes de educação pesquisadas passam por algum tipo de curso de formação, que aborda o trabalho com visitantes (mediação), os conteúdos específicos das atividades presentes nas instituições e o PEFI. Wick (2014) analisou a EA em programas de uso público de três Parques Estaduais no município de São Paulo e percebeu que não existia um processo formalizado de formação das/os monitoras/es que realizavam as atividades educativas nas UCs, o aprendizado acontecia a partir de experiências com pessoas da equipe que estavam há mais tempo na função. Dessa maneira, percebemos que as instituições pesquisadas do PEFI possuem um importante diferencial: a sistematização do processo de formação, característica que, provavelmente, permite que os projetos possam ser desenvolvidos com propriedade pelas/os estagiárias/os destas instituições.

Com relação ao tipo de atividades educativas realizadas, as três instituições seguem características similares de outras com a mesma finalidade, sendo 
visitas monitoradas a atividade mais realizada (Auricchio 1999, Cerati 2008). São utilizadas também placas interpretativas e exposições, permitindo um passeio educativo. Comparando as ações educativas realizadas no PEFI com a realidade de outras UCs, constatamos uma semelhança nas principais atividades promovidas, representadas principalmente pela realização de trilhas, visitas monitoradas, palestras, cursos de formação de professoras/es ou monitoras/es, exposições, atividades com escolas do entorno, entre outras (Toledo \& Pelicioni 2006, Dias 2008, Valenti et al. 2014, Wick 2014).

Como indicamos anteriormente, nenhuma das três instituições possui uma atividade educativa para o público visitante cujo foco principal seja abordar o PEFI. Há apenas o Museu Botânico, no JBSP, no qual parte de uma de suas salas trata do PEFI e uma das placas no Espaço educador "Na trilha da Kinha", na FPZSP. Esta UC é normalmente abordada quando o tema é a Mata Atlântica e também quando há a necessidade de inserir a/o visitante no contexto em que se encontra, representado pelo fato das educadoras informarem que estão situando a/o visitante. Além disso, o modo de se tratar do PEFI pode variar de acordo com quem está realizando a mediação, mesmo que nesses locais existam cursos de formação e materiais de apoio para estudo. A educadora da FPZSP indica essa possibilidade:

"[...] cada monitor tem seu jeito de conduzir a atividade, você tem um roteiro básico, um material de apoio, mas cada um fala da forma que se sente mais à vontade desde que passe a mensagem principal [...]”. Alice 277.

Por outro lado, mesmo que pontualmente, quando o PEFI é abordado, as/os visitantes são apresentadas/ os a esta UC, permitindo a difusão da existência deste local.

Ainda, precisamos considerar que há a possibilidade, durante os momentos de mediação com visitantes, de tratar da realidade das UCs tanto de modo geral como mais específico. Isso pode ser percebido por Wick (2014), uma vez que os monitores dos parques analisados tratavam, além de aspectos ecológicos, o histórico da UC, suas características físicas, a presença de patrimônios histórico-culturais, o entorno e sua comunidade, além de explicações sobre o que são UCs e seus instrumentos de manejo. Nas atividades das instituições pesquisadas, como indicado pela maioria das educadoras, quando possível, são abordados os aspectos socioambientais e a biodiversidade do PEFI, principalmente os serviços que esta UC traz para a população da região. Embora levar em consideração os serviços ambientais seja, de certa forma, perceber esse ambiente com um olhar antropocêntrico, este pode ser um caminho para despertar nas/os visitantes o interesse e respeito não só por esta área, como também por outras similares, em especial UCs urbanas. Como indicado por Dearborn \& Kark (2010), duas das possíveis motivações para conservação da biodiversidade urbana são justamente o fato de realizarem serviços ambientais e promoverem o bem-estar dos seres humanos.

Recomendações para um programa de educação ambiental para o PEFI - A partir dos resultados encontrados e análises realizadas, apresentamos a seguir algumas recomendações para a elaboração de um programa de educação ambiental unificado para a conservação do PEFI. Apresentaremos também as sugestões dadas pelas educadoras entrevistadas.

Retomando a respeito de como o PEFI é abordado pelas três instituições analisadas e sob o ponto de vista de uma EA crítica, que propõe uma leitura de mundo mais complexa e permitir ação diante das questões ambientais (Carvalho 2004, Guimarães 2004), é importante contextualizar e problematizar o assunto abordado, no caso o PEFI. Dessa maneira, seria interessante ir além da apresentação da UC e de seus serviços, trabalhando com as pessoas que visitam as instituições quais são as possíveis problemáticas enfrentadas pela região, como também, das UCs em geral, assim, mesmo que a/o visitante seja de outra cidade ou estado, ela/ele desenvolverá habilidades e posturas não somente para com o PEFI, mas para situações semelhantes à desta UC.

Embora exista este potencial para tratar do PEFI nas atividades das instituições pesquisadas, é necessário considerar outros fatores. Cada uma dessas instituições tem suas demandas e temáticas próprias, necessitando muitas vezes priorizá-las ao invés de abordar o PEFI. Isso reflete o pouco contato da maioria das educadoras em relação ao plano de manejo do PEFI e, mesmo a educadora do JBSP que o conhece, o utiliza apenas para atividades ligadas diretamente com a população do entorno, demonstrando uma separação entre o PEFI e as instituições em seu interior. É claro que isso não ocorre apenas por decisões dessas educadoras, há também a política e direcionamento da diretoria dessas instituições. Então, dependendo da visão dessas pessoas e do relacionamento com as outras instituições no PEFI é que serão realizados os trabalhos. 
Os resultados mostram que as equipes educadoras conseguem apenas suprir as demandas internas das atividades já existentes nessas instituições, impossibilitando a elaboração e implantação de novas atividades, principalmente fora dessas instituições.

Em contrapartida, a necessidade de trabalhos educativos sobre o PEFI e com a população do entorno pode ser justificada a partir de dois importantes documentos. O primeiro é a Estratégia Nacional de Comunicação e Educação Ambiental em Unidades de Conservação (ENCEA), que em suas diretrizes indica a necessidade de consolidar a participação social nos diversos momentos da gestão de UCs e inserir a temática das UCs no ensino não-formal (MMA 2011). Trabalhar com a temática do PEFI e com sua população se enquadram nessas duas importantes diretrizes, que auxiliarão cumprir os objetivos da ENCEA, ou seja, o fortalecimento das UCs e uma efetiva participação social nesses locais, e por consequência, permitirão alcançar os objetivos do PEFI.

O segundo documento é o plano de manejo do PEFI, que define e guia as ações na UC. É a partir de seu cumprimento que os objetivos da UC são alcançados. No plano de manejo do PEFI está descrita a necessidade de um programa educativo para a valorização desta UC, com a proposta de ações voltadas à população do entorno. Neste momento, esta proposta não está sendo cumprida, já que atualmente não existem trabalhos que incluam diretamente essas pessoas. Assim, há a necessidade da implantação de tais ações para o cumprimento das indicações do plano de manejo e consequentes objetivos deste Parque Estadual.

Outro motivo que justifica a necessidade de ações educativas sobre o PEFI e com seu entorno são os resultados positivos já encontrados em experiências com outras UCs como, por exemplo, a redução de impactos ambientais, o despertar de respeito e valorização pela área e por sua biodiversidade, o engajamento e participação da população na conservação da UC e de sua biodiversidade, a melhora de relacionamento entre equipes gestoras e população do entorno, entre outros aspectos (Padua \& ValladaresPadua 1997, Blanco 2001, Bizerril et al. 2011).

Alguns desses importantes resultados já foram inclusive alcançados com o PEFI e seu entorno, por conta das reuniões do Conselho de Compromisso formado entre a população de uma rua adjacente ao PEFI, o Estado e o Município de Diadema. A partir deste projeto, foi percebido o empoderamento da população, bem como foi possível informar as pessoas participantes sobre descarte de lixo em local adequado e buscar estratégias para reduzir o acesso ao PEFI para atos de violência e consumo de drogas (Cerati \& Souza 2009, Cerati et al. 2011). Assim, o projeto possibilitou grande auxílio na resolução dos principais conflitos entre a UC e essa população, o que contribuiu para a gestão da área.

Como forma de iniciar um diálogo para um possível passo à frente em relação a EA no PEFI, pedimos às três educadoras entrevistadas sugestões sobre como envolver a população do entorno com o PEFI. As sugestões estão descritas e categorizadas na tabela 1. Essas sugestões podem ser seguidas para trabalhos futuros cujo enfoque seja a população do entorno do PEFI.

Compreendemos que a EA no PEFI funciona de maneira individualizada em cada uma das instituições. Dessa forma, procuramos saber a opinião das educadoras responsáveis sobre como poderia ser um programa educativo ideal para o PEFI. As características indicadas para esse programa estão descritas na tabela 2 .

As características para um futuro programa de educação ambiental no PEFI indicadas pelas educadoras (tabela 2) foram agrupadas nas categorias descritas a seguir. A primeira delas indica que o programa deve ser interinstitucional. Talvez essa seja a forma de tornar possível a percepção tanto de quem trabalha nas instituições no PEFI, como para quem as visita e para quem vive em seu entorno que este local é uma UC e que como tal possui regras, condicionantes e o objetivo de conservar a biodiversidade. No entanto, as barreiras que citamos anteriormente possivelmente afetariam a elaboração de um programa com essas características, sendo necessário um esforço conjunto para colocá-lo em prática, tanto que esse é um dos motivos pelo qual surge a categoria programa institucional para visitantes, no qual cada instituição realizaria esforços para implementar em seus atuais programas, projetos que tratassem do PEFI e envolvessem a população do entorno. Embora realmente válidos, talvez não sejam tão fortes e até eficazes, como seriam se todas as instituições estivessem envolvidas em um programa único para o PEFI.

Outras categorias são - visão sistêmica, na qual estão incluídas as relações que o PEFI tem com a biodiversidade, seu entorno e a cidade de São Paulo; PEFI como modelo de UC, talvez um possível 
Tabela 1. Sugestões das educadoras para promover o envolvimento da população do entorno com o PEFI.

Table 1. Suggestions from educators to promote the involvement of the surrounding population with PEFI.

\begin{tabular}{llc}
\hline & Sugestões para envolvimento da população do entorno com o PEFI \\
\hline $\begin{array}{l}\mathrm{N}^{\circ} \text { de } \\
\text { participantes }\end{array}$ & Categoria & Exemplo de citação \\
\hline
\end{tabular}

1

1

1

1

1

1

1
Cursos para formação de professoras/es

Parceria com secretarias de São Paulo e Diadema

Divulgação de atividades por lideranças comunitárias ou grupos organizados

Palestras em empresas da região

Palestras para população

Sensibilização promovida pelas instituições do PEFI em conjunto

Buscar as demandas da comunidade e incluí-la no processo de elaboração de atividades
"Eu acho que, em relação ao público escolar, talvez valesse a pena alguma coisa, como a gente faz muitas capacitações pra professores, a gente já tem uma experiência com isso, uma coisa voltada pras escolas dessa região [...]" Alice 385.

"Então, acho que uma parceria. Só que essa parceria envolveria mais de uma Secretaria porque uma parte é São Paulo e outra parte é Diadema, né, já são governos diferentes, então teria que ser uma parceria entre vários municípios." Alice 390.

"[...] eu acho que através de alguma liderança que tenha na comunidade ou de grupos específicos que já sejam organizados, talvez seja mais fácil essa interlocução aqui com o Zoo e com as outras instituições para trazer o pessoal para cá." Alice 398.

"[...] através de grandes empresas que tenham na região e que tenham muitos funcionários que estejam inseridos na comunidade, talvez seja um meio também de entrar, fazer uma palestra na semana do meio ambiente, apresentar o PEFI para essas pessoas, mostrar as opções que eles têm de lazer às vezes com baixo custo, enfim, e a problemática toda da região [...].” Alice 409.

“[...] através das palestras [...]." Carla 484.

“[...] talvez aí os três parques ao mesmo tempo, de nós irmos à comunidade trabalhar uma sensibilização com eles lá." Carla 489.

"[...] entre em contato com essa comunidade, converse com eles e tire deles os problemas, as necessidades, as expectativas e elabore o projeto em conjunto." Bruna 429. modo de permitir a problematização necessária para garantir uma aprendizagem realmente significativa e contextualizada; para todos os públicos, que ressalta a necessidade de se trabalhar não apenas com as crianças, o que é bastante comum em programas e ações de EA, mas também com pessoas adultas, já que estas são responsáveis pelas tomadas de decisão envolvendo a biodiversidade, como indicam Valenti et al. (2015b), que justificam essa possibilidade embasando-se no fato, pela EA crítica, de que a partir do diálogo, todas as pessoas podem aprender umas com as outras; e a consideração do plano de manejo, o qual pode ser um guia para a elaboração do programa educativo.

Finalmente, há as categorias abordar importância do meio ambiente para as pessoas e abordar como tratar o meio ambiente. É importante termos consciência de nossas ações e conhecimento de alternativas para torná-las mais compatíveis com o ambiente, buscando a solução das questões ambientais. Contudo, sob a ótica de uma EA crítica, transformadora e emancipatória, apenas o estímulo a mudanças de comportamento e ações individuais não é suficiente, mas com o desvelamento da realidade e o movimento coletivo da sociedade, por meio de práticas educativas que realizam a formação do sujeito como ser individual e social, inserido em determinado contexto histórico, podemos buscar a solução para os diversos problemas ambientais atuais (Carvalho 2004, Guimarães 2004).

Assim, é interessante para esse programa ir além das mudanças comportamentais e trabalhar com 
Tabela 2. Opinião das educadoras sobre características de um programa educativo para conservação do PEFI.

Table 2. Opinion of educators on the characteristics of an educational program for PEFI conservation.

Características de um programa educativo para o PEFI

\begin{tabular}{lll}
\hline $\mathrm{N}^{\mathrm{o}}$ de & Categoria & Exemplo de citação \\
participantes &
\end{tabular}

$2 \quad$ Interinstitucional

1

Programa institucional para visitantes

1 Visão sistêmica

$1 \quad$ PEFI como modelo de UC

1 Para todos os públicos

1

1

1
Abordar importância do meio ambiente para as pessoas
"Um programa para a conservação do PEFI, em primeiro lugar, deveria agregar as instituições que formam o PEFI, todas as instituições deveriam trabalhar em conjunto para atingir os mesmos objetivos."

Bruna 436

"Acredito que se cada instituição estabelecer um programa de educação ambiental com a população que o visita também teremos bons resultados disso. ” Bruna 445

"Acho que é mostrar que realmente todas as inter-relações que ocorrem dentro do parque e qual é a relação do parque com o seu entorno e de um modo geral, com a cidade de São Paulo e como unidade de conservação [...]" Alice 422.

"[...] qual é a relevância dele como modelo, de repente, para outros fragmentos que estejam na mesma situação, entendeu?" Alice 425.

."Eu acho que ele deve contemplar todos os públicos, né." Alice 418.

"De repente seria interessante ver o que está previsto no plano de manejo do parque para ter uma direção que pudesse ser seguida nesse Programa de Educação Ambiental." Alice 427

"Então eu acho que a educação ambiental, que a gente coloca, que eu acho que tinha que ser no PEFI, pela possibilidade da gente ter aqui na mão uma população tão próxima, uma área tão verde que hoje não existe mais e a importância dela para o dia-a-dia de cada um. Então essa riqueza, não a educação ambiental pra conservação do PEFI propriamente dita, a educação ambiental pela importância do ambiente para a vida de cada um [...]." Carla 501.

"[...] acho que a educação ambiental, quer dizer, o conceito que a gente tenta passar para o visitante é entender que todo esse contexto do ambiente que você está, [...] ele é fundamental pra sua existência e como é que você tem que tratá-lo, né, para que ele continue dentro de um convívio te trazendo coisas positivas [...]." Carla 496. questões da realidade local, pois dessa forma, ao invés de se utilizar de questões ambientais mais globais, será possível sensibilizar e possibilitar a participação das cidadãs e cidadãos (Dorado et al. 2002). Além disso, Valenti et al. (2015a), ao analisarem as ações realizadas no Parque Estadual da Serra do Mar Núcleo Picinguaba (SP), demonstram que é possível que atividades de EA em UCs trabalhem com uma tendência crítica, uma vez que na grande maioria dos parâmetros utilizados para verificar as atividades desta $\mathrm{UC}$, essa foi a tendência que mais surgiu.

\section{Considerações finais}

Por meio desta pesquisa procuramos compreender aspectos do desenvolvimento da EA no PEFI e a participação da população do entorno nas atividades educativas. Pudemos perceber que o PEFI é um Parque Estadual bastante diferenciado de outras UCs tanto em sua categoria quanto com relação às outras existentes. Isso acontece, pois em seu interior existem instituições estabelecidas, ligadas ao governo estadual, que influenciam na dinâmica da UC. 
Por conta dessa característica, os resultados indicaram que não existe uma identidade do PEFI como uma UC. Logo, podemos inferir que as pessoas que trabalham nas instituições mencionadas têm dificuldade em reconhecer a dimensão do PEFI enquanto uma Unidade de Conservação e, consequentemente, têm a percepção de separação entre UC e instituições, o que dificulta a compreensão de que as instituições estão inseridas no PEFI.

Devido à ausência de atividades educativas que abordem o PEFI, bem como ações que incluam diretamente a população do entorno no programa educativo das instituições pesquisadas, buscamos nesta pesquisa sugestões das três entrevistadas para que trabalhos com estes objetivos possam ser realizados. Todas essas sugestões são bastante adequadas à realidade do PEFI e podem subsidiar tanto a gestão da UC quanto as instituições no PEFI, de maneira a direcionar novos trabalhos educativos para a conservação da área. Uma sugestão que merece destaque é a necessidade da integração das atividades de EA no PEFI, em busca de se passar uma mesma mensagem e também unir esforços para este objetivo. Contudo, foram apontadas algumas barreiras para que isso fosse possível, principalmente relacionada a um apoio político institucional mais efetivo.

Defendemos a necessidade desse movimento em direção à integração da EA no PEFI e de sua discussão coletiva, pois essa constitui a ação ideal e necessária para que a UC possa se fortalecer e se manter, alcançando seus objetivos de conservação. No entanto, devemos considerar que estes processos demandam tempo, vontade pessoal e política, e não dependem de apenas uma ou outra pessoa, e sim de todo um grupo para que isso se torne possível. Deste modo, um trabalho de longo prazo é necessário, para que primeiramente se estabeleçam relações de confiança e parceria entre os grupos envolvidos, podendo então ser formado um grupo de trabalho com essa finalidade.

Este processo pode, por exemplo, ser iniciado a partir de parcerias entre as equipes de EA das instituições e as associações de bairro, desenvolvendo atividades em conjunto e estabelecendo oportunidades de troca de experiências. Uma dessas atividades pode estar relacionada com a formação das equipes educadoras das instituições, promovendo diálogos com lideranças comunitárias e/ou outras pessoas moradoras da região; outra atividade sugerida seria a realização de caminhadas pelo entorno das instituições. A partir de ações como essas será possível conhecer a realidade do entorno e as relações que existem com o PEFI, bem como poderá fortalecer a imagem do PEFI como $\mathrm{UC}$, tanto para as equipes quanto para a população do entorno.

Para fortalecer e auxiliar no direcionamento das ações de EA no PEFI, indicamos a consideração da Estratégia Nacional de Comunicação e Educação Ambiental em Unidades de Conservação (ENCEA). Este documento traz diretrizes e estratégias para a EA e comunicação nas UCs que possibilitam justamente a busca pela resolução de conflitos e o fortalecimento dessas áreas. Assim, é interessante que a gestão do PEFI se utilize da ENCEA como um guia para ações, principalmente envolvendo a população do entorno.

Finalmente, acreditamos que a perspectiva dialógica é crucial para atingir a integração da EA no PEFI. Ela aproximará os grupos sociais envolvidos com a UC, pois com a compreensão da realidade do outro e a consideração por suas opiniões, é possível a construção coletiva e democrática de caminhos a serem trilhados para a conservação do PEFI. Dessa maneira, esperamos que esta pesquisa tenha trazido elementos para impulsionar este diálogo, bem como salientar o grande potencial que o PEFI possui em se tornar uma UC com processos educativos que além de permitir a conservação da área, possibilitar a formação de pessoas engajadas e que possam participar cada vez mais das tomadas de decisão tanto nesta UC como na sociedade.

\section{Agradecimentos}

Agradecemos a Universidade Federal de São Carlos e a Fundação Parque Zoológico de São Paulo por tornarem possível a realização desta pesquisa e pela bolsa concedida.

\section{Literatura citada}

Auricchio, A.L.R. 1999. Potencial da educação ambiental nos zoológicos brasileiros. Publicações avulsas do Instituto Pau-Brasil de História Natural 1: 1-46.

Barbosa, L.M., Potomati, A. \& Peccinini, A.A. 2002. O PEFI: histórico e legislação. In: D.C. Bicudo, M.A. Forti \& C.E.M. Bicudo (orgs.). Parque Estadual das Fontes do Ipiranga: unidade de conservação que resiste à urbanização de São Paulo. Secretaria do Meio Ambiente do Estado de São Paulo, São Paulo, pp. 16-28.

Bizerril, M.X.A., Soares, C.C. \& Santos, J.P. 2011. Linking community communication to conservation of the maned wolf in central Brazil. Environmental Education Research 17: 815-827.

Blanco, N.C.P. 2001. Educación ambiental en el sistema de parques nacionales de Venezuela. Tópicos en Educación Ambiental 3: 55-69. 
Brasil. 1981. Lei n. 6.938, de 31 de agosto de 1981. Dispõe sobre a Política Nacional do Meio Ambiente, seus fins e mecanismos de formulação e aplicação, e dá outras providências. Disponível em http://www.planalto.gov. br/ccivil_03/leis/L6938.htm (acesso em 1-III-2019).

Brasil. 1988. Constituição da República Federativa do Brasil de 1988. Disponível em http://www.planalto. gov.br/ccivil_03/constituicao/ConstituicaoCompilado. htm (acesso em 1-III-2019).

Brasil. 1999. Lei n. 9.795, de 27 de abril de 1999. Dispõe sobre a educação ambiental, institui a Política Nacional de Educação Ambiental e dá outras providências. In: H.T Oliveira \& A. Logarezzi (orgs.). Marcos de referência para educação ambiental: da teoria à prática e do local ao global. Universidade Fedral de São Carlos, São Carlos.

Brasil. 2000. Lei n. 9.985, de 18 de julho de 2000. Regulamenta o art. 225, § 1o, incisos I, II, III e VII da Constituição Federal, institui o Sistema Nacional de Unidades de Conservação da Natureza e dá outras providências. Disponível em http://www.planalto.gov. br/ccivil_03/LEIS/L9985.htm (acesso em 1-III-2019).

Brasil. 2002. Decreto n. 4.281, de 25 de junho de 2002. Regulamenta a Lei no 9.795, de 27 de abril de 1999, que institui a Política Nacional de Educação Ambiental, e dá outras providências. In: H.T Oliveira \& A. Logarezzi (orgs.). Marcos de referência para educação ambiental: da teoria à prática e do local ao global. Universidade Federal de São Carlos, São Carlos.

Brasil. 2005. Programa Nacional de Educação Ambiental. 3 ed. MMA/MEC, Brasília.

Brasil. 2006. Decreto n. 5.758, de 13 de abril de 2006. Institui o Plano Estratégico Nacional de Áreas Protegidas PNAP, seus princípios, diretrizes, objetivos e estratégias, e dá outras providências. Disponível em http://www. planalto.gov.br/ccivil_03/_Ato20042006/2006/Decreto/ D5758.htm (acesso em 1-III-2019).

Carvalho, I.C.M. 2004. Educação ambiental crítica: nomes e endereçamentos da educação. In: P.P. Layrargues (coord.). Identidades da Educação ambiental brasileira. Ministério do Meio Ambiente, Brasília, pp. 13-24.

Cerati, T.M. (org.). 2011. O jardim botânico vai à escola: a experiência dos jardins botânicos brasileiros. Instituto de Botânica, São Paulo.

Cerati, T.M. 2008. A utilização de coleções vivas para educação ambiental. In: Anais da $16^{\text {a }}$ Reunião de Jardins Botânicos Brasileiros, São Paulo. Rede Brasileira de Jardins Botânicos, Rio de Janeiro, pp. 35-38.

Cerati, T.M., Matheus, D.R., Souza, A.Q. \& Bonomo, M.D.R. 2011. Gestão participativa em uma unidade de conservação urbana: a busca de estratégias para conservar o Parque Estadual das Fontes do Ipiranga, São Paulo, Brasil. Revista Interfacehs 6: 3-19.
Cerati, T.M. \& Souza, A.Q. 2009. Educação ambiental e percepção: o caso do Parque Estadual das Fontes do Ipiranga, São Paulo, Brasil. Revista eletrônica do Mestrado em Educação Ambiental 23: 232-250.

Dearborn, D.C. \& Kark, S. 2010. Motivations for conserving urban biodiversity. Conservation biology 24: 432-440.

Dias, C.M. 2008. Poder público, processo educativo e população: o caso da Estação Ecológica De Angatuba, SP, Brasil. Dissertação de Mestrado, Universidade Estadual Paulista "Julio de Mesquita Filho", Rio Claro.

Dorado, O., Arias, D.M., Alonso, G. \& Maldonado, B. 2002. Educación ambiental para la biodiversidad en el trópico seco, Reserva de la Biosfera Sierra de Huautla, Morelos, México. Tópicos en Educación Ambiental 4: 23-33.

Fernandes, A.J., Reis, L.A.M. \& Carvalho, A. 2002. Caracterização do meio físico. In: D.C. Bicudo, M.A. Forti \& C.E.M. Bicudo (orgs.). Parque Estadual das Fontes do Ipiranga: unidade de conservação que resiste à urbanização de São Paulo. Secretaria do Meio Ambiente do Estado de São Paulo, São Paulo, pp. 49-62.

FPZSP (Fundação Parque Zoológico de São Paulo). 2014. Relatório anual da Fundação Parque Zoológico de São Paulo. Fundação Parque Zoológico de São Paulo, São Paulo.

FPZSP (Fundação Parque Zoológico de São Paulo). 2019. A fundação. Disponível em http://www.zoologico. com.br/a-fundacao (acesso em 2-III-2019).

Godoy, A.S. 1995a. Introdução à pesquisa qualitativa e suas possibilidades. Revista de administração de empresas 35: 57-63.

Godoy, A.S. 1995 b. Pesquisa qualitativa: tipos fundamentais. Revista de administração de empresas 35: 20-29.

Guimarães, M. 2004. Educação ambiental crítica. In: P.P. Layrargues (coord.). Identidades da Educação ambiental brasileira. Ministério do Meio Ambiente, Brasília, pp. 25-34.

Jardim Botânico de São Paulo. 2015. Visitas educativas. Disponível em http://jardimbotanico.sp.gov.br/ educacao-ambiental/visitas-educativas/ (acesso em 16-XI-2015).

Lüdke, M. \& André, M.E.D.A. 1986. Pesquisa em educação: abordagens qualitativas. EPU, São Paulo.

Mantovani, M.S.M. \& Massambani, O. 2004. Ciência e tecnologia no parque. EdUSP, São Paulo.

Martins, C., Rancura, K.G.O., Oliveira, H.T., Aranda, B.H, Araújo-Bissa, C.H., Pinto, C.M., Campos, F.T.V., Manoel, I.S. \& Oliveira, L.R. 2015. Na Trilha da Kinha: atividades de educação ambiental para a conservação do mico-leão-preto. Disponível em http:// www.zoologico.com.br/wp-content/uploads/2013/07/ Atividades-Na-Trilha-da-Kinha-Versao-Final.pdf (acesso em 4-III-2019). 
Mendonça, R. 2005. Conservar e criar: natureza, cultura e complexidade. Senac Editora, São Paulo.

Mendonça, R. 2007. Educação ambiental vivencial. In: L.A. Ferraro-Júnior (org.). Encontros e caminhos: formação de educadoras(es) ambientais e coletivos educadores. Ministério do Meio Ambiente, Brasília. pp. 117-129.

Menghini, F.B., Moya-Neto, J. \& Guerra, A.F.S. 2007. Interpretação ambiental. In: L.A. Ferraro-Júnior (org.). Encontros e caminhos: formação de educadoras(es) ambientais e coletivos educadores. Ministério do Meio Ambiente, Brasília, pp. 211-217.

MMA (Ministério do Meio Ambiente). 2011. Diretrizes para estratégia nacional de comunicação e educação ambiental em unidades de conservação. MMA, Brasília.

Moraes, R. \& Galiazzi, M.C. 2007. Análise textual discursiva. Ed. Unijuí, Ijuí.

Oliveira, H.T. \& Logarezzi, A. 2013. Marcos de referência para educação ambiental: da teoria à prática e do local ao global. UFSCar, São Carlos.

Padua, S. M. \& Valladares-Padua, C. 1997. Um programa integrado para a conservação do mico-leão-preto (Leontopithecus chrysopygus) - Pesquisa, Educação e Envolvimento Comunitário. In: S.M. Padua \& M. Tabanez (org.). Educação Ambiental: Caminhos trilhados no Brasil. IPÊ - Instituto de Pesquisas Ecológicas, Brasília, pp. 119-131.

Padua, S.M. 2012. Educação ambiental em unidades de conservação. In: M.O. Cases (org.). Gestão de unidades de conservação: compartilhando uma experiência de capacitação. WWF Brasil/IPÊ-Instituto de Pesquisas Ecológicas, Brasília, pp.203-213.

Roberti, F.A.V.V.\& Rancura, K.G.O. 2010. A Mata Atlântica como instrumento de ensino. Fundação Parque Zoológico de São Paulo, São Paulo.
Rocha, L.M. 1997. Unidades de conservação e organizações não-governamentais em parceria: programas de educação ambiental. In: S.M. Padua \& M.F. Tabanez, (orgs.). Educação ambiental: caminhos trilhados no Brasil. Instituto de Pesquisas Ecológicas - IPÊ, Brasília, pp. 237-245.

SMA (Secretaria de Meio Ambiente do Estado de São Paulo). 2008. Plano de manejo do Parque Estadual das Fontes do Ipiranga. Instituto de Botânica.

Toledo, R.F. \& Pelicioni, M.C.F. 2006. A educação ambiental nos parques estaduais paulistas. Revista Brasileira de Ciências Ambientais 3: 27-31.

Triviños, A.N.S. 1987. Introdução à pesquisa em ciências sociais: a pesquisa qualitativa em educação. Editora Atlas, São Paulo.

Valenti, M.W, Oliveira, S.M., Miotto, R.A. \& Oliveira, H.T. 2014. Educação ambiental e a conservação da onça parda: potenciais das unidades de conservação do nordeste paulista. Revista do Instituto Florestal 26: 55-69.

Valenti, M.W., Iared, V.G. \& Oliveira, H.T. 2015a. Potencial das atividades de uso público do Núcleo Picinguaba do Parque Estadual da Serra do Mar (SP) para uma educação ambiental crítica. Ciência \& Educação 21: 709-724.

Valenti, M.W., Oliveira, H.T. \& Logarezzi, A.J.M. 2015b. Exclusory and transformative dimensions of adult environmental education in two Brazilian protected areas. Environmental Education Research 23: 675-686.

Wick, M.A.L. 2014. A educação ambiental presente nos programas de uso público em parques estaduais localizados no município de São Paulo. Dissertação de Mestrado, Universidade Estadual Paulista "Julio de Mesquita Filho", Rio Claro. 